\title{
Open-field and response-flexibility measures in the rat
}

\author{
BRITT ANDERSON \\ Keesler Technical Training Center Medical Center \\ Keesler Air Force Base, Biloxi, Mississippi
}

\begin{abstract}
It has been suggested that rat response flexibility is a unique problem-solving mechanism related to intelligence. If so, response-flexibility task performance should not be explainable in terms of individual differences in other rat behavioral characteristics. Therefore, to assess the validity of the claim that rat response flexibility is a unique process, response flexibility was measured in Sprague-Dawley rats $(n=20)$ and compared with estimations of emotionality, exploration, and attention to novelty (all from an open-field test) and learning and motivation (both from the response-flexibility test). There were no significant correlations. This result supports the contention that response-flexibility tasks assess a unique attribute of the rat. Further studies are required to validate the claim that rat response flexibility is related to intelligence.
\end{abstract}

The term response flexibility refers to the capacity of a rat to attempt new routes to a goal when a previously successful route is obstructed. It has been suggested that response flexibility can be used as a measure of rat intelligence (Thompson, Bjelajac, Huestis, Crinella, \& Yu, 1989), and that it is a unique problem-solving mechanism within the larger measure of detour problem solving, wherein performance is affected by both response flexibility and learning. Thus response flexibility has been used in a lesion survey, in an attempt to localize a general anatomic circuit subserving intelligence in the rat (Thompson, Crinella, \& Yu, 1990). The implication of Thompson and coworkers is that rat intelligence is in part assessed by response-flexibility measures and that rat intelligence is a model of human intelligence. Consequently, rats with lesions in select areas of the brain can be viewed as mentally retarded (Thompson, Huestis, Crinella, \& Yu, 1987). But this claim currently rests only on the intuitive appeal that the selected rat behaviors can be used by researchers to assess the same brain mechanisms that human detour tasks measure. If the claim of rat and human parity is to be accepted, some demonstration of validity of the use of the rat's behavior as a measure is required.

To demonstrate internal validity, the rat response flexibility task must be shown to be reliable. Thompson,

\footnotetext{
The opinions expressed herein are those of the author and do not purport to express those of the Department of the Air Force or the Department of Defense. This is a work of the United States government and not subject to copyright in the United States. All animals were handled in accordance with the Animal Welfare Act and its amendments, AFR 169-2 (The Use of Animals in DOD Programs), and the NIH Guide for the Care and Use of Laboratory Animals. The work was performed under United States Surgeon General Clinical Investigation No. 90-055. The author would like to thank the Keesler Clinical Research Laboratory staff, especially Harry Slack and Herbert Robles. Correspondence should be addressed to Britt Anderson, Department of Neurology, University of Alabama, UAB Station, Birmingham, AL 35294-0007.
}

Harmon, and Yu (1984) have done this in part, by showing high correlations between response-flexibility scores obtained on the same basic task measured on 3 consecutive days. A stronger demonstration of internal validity would require stability of performance across longer periods of time.

Validation of the claim that response-flexibility tasks assess a unique aspect of rat behavior would require that no important correlation be found between responseflexibility task performance and other, individually variable, rat behavioral characteristics, such as emotionality and activity level. Finally, support of the claim that rat response flexibility is related to human intelligence would require a demonstration that rat response flexibility correlates with measures known to correlate with human intelligence.

This report details an initial evaluation of those issues. First, rats were assessed on the same response-flexibility task 6 days apart to assess the stability of performance across time. Second, rat response-flexibility task performance was compared with measures of emotionality, exploration, motivation, and learning, to evaluate the degree of uniqueness of the response-flexibility process. This evaluation made use of the heterogeneous factors that contribute to open-field performance-results that stem from a paradigmatic example of a rat behavior validation study (Dennenberg, 1969). Third, rat response-flexibility performance was correlated with a measure of attention to novelty, since attention to novelty has been able to predict the later life IQ of human infants (Bornstein \& Sigman, 1986; Fagan \& Singer, 1983).

\section{METHOD}

\section{Animals and Housing}

Four timed-pregnant Sprague-Dawley rats (Harlan SpragueDawley Indianapolis, IN) were delivered at our laboratory. The offspring were randomly assorted among the mothers on Postnatal 
Day 1. Two of these litters, comprising 10 animals each (8 females total), were intended as controls for a drug study and all received $10 \mu l$ water per gram of weight injected subcutaneously on Postnatal Days 1-21; weaning took place on Day 21. When problems occurred with the treatment groups, the control animals were recruited for this study. They received no other treatment and have not been reported as part of any other study. After weaning, the animals were housed 2 or 3 to a hanging plastic cage and handled at least once a week until testing began at 90 days of age. The housing room was on a 12:12-h light:dark cycle (lights on at 6:00 a.m.). Food and water were provided ad lib, except as specified below. Since this project was concerned with covariation of behavioral scores and not absolute levels of performance, the possibility of altered absolute performance secondary to the early life injection was not an issue. For example, if the animal was more "emotional" as a result of early life injections, all tests sensitive to emotionality should change proportionally.

\section{Apparatus and Procedure}

Open field. This apparatus was used to measure emotionality, exploration tendencies, and attention to novelty. The perimeter was constructed of unpainted pine that enclosed a square with $60-\mathrm{cm}$ sides. The height of the walls was $30 \mathrm{~cm}$. The floor was a Plexiglas sheet containing a grid of 16 equally sized squares, $15 \mathrm{~cm}$ on a side. During testing, the box was placed on the floor of the test room, which was lit by fluorescent lights. Testing took place between 8:00 and 12:00 p.m. on 5 consecutive days. From the home cage, which was in the room next door, each animal was individually brought in a plastic cage to the test room. The animal was placed in the comer of the open field to the right of the technician, facing the corner. The squares entered by both forepaws were counted for $3 \mathrm{~min}$. On Day 4 , the amount of time spent in the 4 squares forming the corner opposite the technician was recorded with a stopwatch. On Day 5, a metal nut, a white plastic IV tubing clamp, and a red syringe cover were placed in the comer opposite the technician, and the amount of time the rat spent in those 4 squares was again recorded. The number of squares entered on Day 1 was taken as a measure of emotionality (Dennenberg, 1969). The total number of squares entered on Days 2, 3, and 4 was the measure of exploration (Dennenberg, 1969). The number of seconds spent in the area of interest on Day 5 minus the number of seconds spent in the same area on Day 4 was the measure of attention to novelty.

Response nexibility. This apparatus and protocol were adapted from those reported by Thompson et al. (1984). The enclosure was constructed of thin cabinet wood to make a single large chamber containing three compartments. The start chamber $(23 \times 23 \mathrm{~cm})$ was painted flat white and separated from the choice chamber $(60$ $\times 55 \mathrm{~cm}$ ), also painted flat white, by a clear Plexiglas guillotine door. The choice chamber was separated from the black goalbox $(30 \times 55 \mathrm{~cm})$ by a $5-\mathrm{cm}$-square opening in the middle of the base of the wall dividing them. The walls were $30 \mathrm{~cm}$ high. The top was covered with clear Plexiglas.

Before beginning this measure, the animals were water deprived for $48 \mathrm{~h}$. No water was available in the home cage until the end of Day 6. Testing was conducted individually, in the same room as had been used for the open-field test. On the 1st day in the chamber (Day 3), the animal was placed in the startbox and the door was raised. After the animal had entered the choice chamber, the door was closed, and the animal was allowed $10 \mathrm{~min}$ in the apparatus. Water was available in a dish in the goalbox. This procedure was repeated on Day 4. On Day 5, a plane of wood, painted white, was placed in the choice chamber so that it started at the floor adjacent to the wall dividing the choice and goal chambers and sloped up toward the start chamber, reaching a height of $10 \mathrm{~cm}$. The inclined plane stretched from wall to wall and was $35 \mathrm{~cm}$ long. Acquiring the water now required the rat to ascend the plane and walk down it to the aperture that led into the goalbox. The animal was started in the startbox and the door opened. The animal was timed for leaving the start chamber as a measure of motivation, timed for placing all four paws in the goalbox, and scored on errors. An error for this problem, Problem A, was defined as the placement of head and both forepaws under the inclined plane. After the rat had entered the goal chamber, it was allowed $10 \mathrm{~min}$ to drink. The rat was free to go back and forth between the goal chamber and choice chamber. If, 5 min after entering the goalbox, the animal failed to drink for more than $60 \mathrm{sec}$, it was removed.

On the following day, the inclined plane was removed and an obstruction in the shape of a $\mathrm{V}$ was put in its place. This structure was made of wood and painted white. The apex of the $V$ was $5 \mathrm{~cm}$ in front of the entrance to the goalbox. The sides of the $V$ came forward to end at the point at which the inclined plane had ended. Each side was $5 \mathrm{~cm}$ from the wall. The sides were $20 \mathrm{~cm}$ tall. For successful performance on this trial, the animal had to navigate around the edge of the obstruction. Entering the V-shaped obstruction with the head and forepaws was counted as an error. The same measures were collected, and the same procedure was used, as on the preceding day. This was Problem B. After its return to the home cage, the rat was allowed free access to water for 3 days. Then it was again waterdeprived for $48 \mathrm{~h}$. Testing was again commenced with the inclined plane in place for 3 consecutive days, 1 trial per day. The time to enter the goalbox on the first exposure to each problem, as well as the number of errors made on that problem, were taken as the measures of response flexibility (Thompson et al., 1984). The improvement in performance on the second 3-day exposure to Problem A was taken as a measure of learning (Thompson et al., 1984).

\section{RESULTS}

The results for the open-field and response-flexibility measures are shown in Table 1 . The number of rats that reached the learning criterion of 1 or 0 errors on Trial 4 of Problem A was $19(n=20)$.

No significant correlation was found for either time or error measures of response flexibility on Trial 1 of Problem A or Problem B with the measures of emotionality, exploration, learning, motivation, or attention to novelty. (All correlations were Pearson product moment, with $n=20$. An important correlation was defined as greater than .5 or less than -.5 ; such a correlation would be statistically significant for this number of subjects and explain at least $25 \%$ of the variance.)

There was a trend for the females to explore more in the open field and to solve the response-flexibility measures with fewer errors and faster, but these measures were not significant statistically (significance defined for

Table 1

Open-Field and Response-Flexibility Results

\begin{tabular}{|c|c|}
\hline \multicolumn{2}{|c|}{ Open-Field Test } \\
\hline $\begin{array}{l}\text { Emotionality } \\
\text { Exploration } \\
\text { Attention to novelty }\end{array}$ & $\begin{array}{l}49.45 \text { squares entered }( \pm 2.87) \\
202.25 \text { squares entered }( \pm 14.72) \\
14.02 \mathrm{sec}( \pm 4.79 \mathrm{sec})\end{array}$ \\
\hline \multicolumn{2}{|c|}{ Response-Flexibility Test } \\
\hline $\begin{array}{l}\text { Problem A } \\
\text { Time } \\
\text { Errors }\end{array}$ & $\begin{array}{l}109.25 \mathrm{sec}( \pm 27.72 \mathrm{sec}) \\
4.65( \pm 0.44)\end{array}$ \\
\hline $\begin{array}{l}\text { Problem B } \\
\text { Time } \\
\text { Errors }\end{array}$ & $\begin{array}{l}14.01 \mathrm{sec}( \pm 1.64 \mathrm{sec}) \\
1.30( \pm 0.09)\end{array}$ \\
\hline
\end{tabular}

Note-Response-flexibility results are for Trial 1 on Problem $A$ and Problem B. Standard error of the mean is given in parentheses. 
two-tailed $t$ test, $p<.05, d f=18$ ), despite the performance of multiple $t$ tests.

The correlations (Pearson product moment) for the number of squares crossed in the open field on Days 2, 3 , and 4 ranged from 0.55 to 0.74 , supporting their grouping as a single measure. The mean numbers of squares entered by all 20 rats on Days 3 and 4 were significantly greater than the mean number of squares entered by the same rats on Day 2 (two-tailed, $t$ test, $p<.05, d f=18$ ).

The correlations between time to solve and number of errors on Trial 1 of Problems A and B were 0.53 and 0.44 , respectively. The measure of response flexibility with Problem $\mathrm{A}$ appeared valid. While both time and error scores improved between Trial 1 and Trial 2, separated by 6 days, on Problem A the correlations of time and error measures between Trials 1 and 2 were 0.91 and 0.53 , respectively.

\section{DISCUSSION}

The basic finding was that there were no important correlations between emotionality, exploration, motivation, or learning and response-flexibility performance. It can be concluded that the response-flexibility measures used are not simply surrogates for emotionality, exploration, motivation, or learning, and that response flexibility can be used to assess a unique capacity. Offering no support to the contention that response flexibility is akin to intelligence is the lack of a relationship between response flexibility and attention to novelty. In consideration of this conclusion, it will be useful to discuss the validity of the measures and their ability to reveal the associations that were sought.

The estimations of emotion and exploration used the open field, a venerable psychological task for their measure. The decision to suggest certain days as reflecting emotion or exploration was based on the arguments of Dennenberg (1969). The moderate correlations of Days 2,3 , and 4 in the open field support the notion that these days measured some common factor. The increase in the mean number of squares entered by the rats on Days 3 and 4 as opposed to Day 2 suggests that anxiety may have been decreased among the rats. It has been shown that anxiolytics may increase exploration into open lighted areas, implying that increased exploration correlates with decreased anxiety (Green, 1991). The attention-to-novelty measure also seems valid. The fact that the vast majority of animals $(16 / 20)$ spent more time in the area containing the novel objects than they did in the same area on the previous day demonstrates that our rats paid attention to new aspects of the environment, as has also been shown before (e.g., Poucet, 1989). We selected as our measure of attention to novelty the raw difference in time between the two exposures on Days 4 and 5 , rather than a percent or ratio, because of the problem involved in making percent comparisons when the subjects start from different baselines (Jorm, 1990).
The animals did not show correlations between response flexibility and emotion, exploration, motivation, or learning; was this because the number of animals was too small? The number of animals was selected so that we could get all of them through the behavioral measures at one time, thereby to avoid any additional variation that might result from testing some animals on one day and other animals later. The downside to this approach is that it makes the number of animals that can be studied relatively small. Despite the small number of animals, important relationships should have been detected; indeed they were detected. For example, the intercorrelations of squares entered on Days 2, 3, and 4 of the open field were all significant. The time and error measures on the response-flexibility measures were significantly correlated, as would be expected. In short, expected correlations were found in the study. The inability to show a correlation with the number of rats does not prove that absolutely no correlation between these variables and response flexibility is present, but it does suggest that if a correlation is present, it contributes little to performance. Thus, confirming the impression of internal validity for the response-flexibility task, there was an important correlation between performance on a first trial and a second trial 6 days later. In validation of the uniqueness of response flexibility behavior, there was no important correlation with other behavioral variables. Here a lack of correlation tended to confirm the hypothesis. However, for validating the claim of a relationship between rat response flexibility and intelligence there was also a lack of correlation, which tended to disconfirm the hypothesis.

The inability to show a correlation between attention to novelty and response flexibility does not permit the conclusion that response flexibility measures some aspect of intelligence. Attention to novelty was selected because evidence showed that this measure in human infants can predict later measurements of IQ (Bornstein \& Sigman, 1986; Fagan \& Singer, 1983). A test that can be applied to human infants-to preverbal creatures with limited motor responses-seemed something that could be applied to rats. Although the testing measure used here was not an exact duplicate of the testing measure applied to humans, the essence of that measure was modeled by assessing the amount of time that the individual spent attending to novel and competing familiar objects. The failure to find a correlation could have occurred for several reasons. First, there may not be one. Second, the attention-to-novelty measure in human infants may best reflect subsequent verbal development, and it may therefore be inappropriate to assess it in the rat. Third, the correlation may have been too small to detect in the number of rats studied here. Since in this situation a cause of response flexibility was not being sought, but rather a relation similar to that observed for human intelligence, more animals might be required for one to confidently detect the 0.3 to 0.4 correlation value that has been reported for human infants. 
Other methods of trying to establish some external validity would be to look at relationships between measures of habituation and response flexibility, since habituation is often disordered in humans with subnormal intelligence and may predict intelligence in normals (Gandhavadi \& Melvin, 1989; Schafer, 1984; Schafer \& Peeke, 1982). Furthermore, conditions that cause mental retardation (e.g., microcephaly) in humans should impair response-flexibility performance in animal models (such as the methylazoxymethanol-treated rat). Finally, there should be correlations between response flexibility and other measures of nonlearned intelligent performance in rats, such as Maier's reasoning (Maier \& Schneirla, 1935). Such comparative measures are being undertaken.

Whether one regards human intelligence as a single capacity or as a unitary term applied to a compilation of more basic abilities, there is still something about our fellow humans that allows us to agree in general about their relative smartness. That alone would make intelligence interesting, but this same capacity is disordered in mental retardation and dementia, which gives special urgency to research on its biological basis. Because of technical and ethical limitations, direct research on human subjects is very difficult, so of course these issues have been examined in animals. Before work proceeds too far, it is important that the suppositions regarding analogies between animal behavior and human intelligence be empirically verified. Since the precise nature of human intelligence is unknown, this will of need be indirect. The work outlined above represents an attempt to look at one suggested "intelligent" animal behavior in this way. As discussed, the "intelligent" animal behaviors can be scrutinized for correlation with attention to novelty as well as other variables. Only when the measurement instruments themselves have been shown to be consistent and valid and the parallels to human intelligence become multiple and reproducible will we be able to make any inferences about the operative human brain mechanisms from the study of "intelligent" animal behavior.

\section{REFERENCES}

Bornstein, M. H., \& Sigman, M. D. (1986). Continuity in mental development from infancy. Child Development, 57, 251-274.

DENNENBERG, V. H. (1969). Open field behavior in the rat: What does it mean? In E. Tobach (Ed.), Experimental approaches to the study of emotional behavior (Annals of the New York Academy of Sciences, Vol. 159, pp. 852-859). New York: New York Academy of Sciences.

FAGAN, J. F., III, SINGER, L. T. (1983). Infant recognition as a measure of intelligence. In L. P. Lipsitt \& C. K. Rovee-Collier (Eds.), Advances in infancy research (Vol. 2, pp. 31-78). Norwood, NJ: Ablex.

GrEeN, S. (1991). Benzodiazepines, putative anxiolytics and animal models of anxiety. Trends in Neuroscience, 14, 101-104.

GaNdhavad, B., MelVin, J. L. (1989). Habituation of optically evoked blink reflex in mentally retarded adults. Joumal of Mental Deficiency Research, 33, 1-11.

JoRM, A. J. (1990). Some pitfalls in data analysis. In R. J. Wurtman, S. Corkin, J. H. Growdon, \& E. Ritter-Walker (Eds.), Advances in neurology: Vol. 51. Alzheimer's disease (pp. 35-39). New York: Raven Press.

Maier, N. R. F., Schneirla, T. C. (1935). Principles of animal psychology. New York: McGraw-Hill.

POUCET, B. (1989). Object exploration, habituation, and response to spatial change in rats following septal or medial frontal cortical damage. Behavioral Neuroscience, 103, 1009-1016.

SCHAFER, E. W. P. (1984). Habituation of evoked cortical potentials correlates with intelligence. SPR Abstracts, 21, 597.

Schafer, E. W. P., \& PezKe, H. V. (1982). Down syndrome individuals fail to habituate cortical evoked potentials. American Joumal of Mental Deficiency, 87, 332-337.

Thompson, R., Buelajac, V. M., Huestis, P. W., Crunella, F. M., \&U, J. (1989). Inhibitory deficits in rats rendered "mentally retarded" by early brain damage. Psychobiology, 17, 61-76.

Thompson, R., Crinella, F. M., YU, J. (1990). Brain mechanisms in problem solving and intelligence: A lesion survey of the rat brain. New York: Plenum.

ThOmpson, R., HARMon, D., * YU, J. (1984). Detour problem-solving behavior in rats with neocortical and hippocampal lesions: $A$ study of response flexibility. Physiological Psychology, 12, 116-124.

Thompson, R., Huestis, P. W., Crinella, F. M., * YU, J. (1987). Further lesion studies on the neuroanatomy of mental retardation in the white rat. Neuroscience \& Biobehavioral Reviews, 11, 415-440.

(Manuscript received May 21, 1991; revision accepted for publication August 29, 1991.) 